\title{
APUNTES CRÍTICOS SOBRE EL CONTROL JUDICIAL DE CONSTITUCIONALIDAD EN EL ECUADOR
}

\author{
Critical notes on judicial control of constitutionality in \\ Ecuador
}

\author{
Gonzalo M. Gaibor Gallardo \\ Doctorando en Derecho Constitucional \\ Universidad Autónoma de Madrid \\ gonzalo.gaibor@estudiante.uam.es
}

http://dx.doi.org/10.18543/ed-68(2)-2020pp97-114

Recibido: 20.11 .2020

Aceptado: $21.12 . .2020$

\section{Resumen}

La aprobación de la Constitución de la República del Ecuador (CRE) en el año 2008 marcó un giro transcendental en el paradigma del derecho constitucional ecuatoriano. A partir de este momento, y a la luz del nuevo estado de derechos y justicia social consagrado en la Constitución, se concibe por primera vez a la Corte Constitucional (CC) como un organismo especializado e independiente de las demás funciones del Estado. Es preciso dejar sentado que durante el siglo XX también se instituyeron Tribunales Constitucionales, sin embargo, la estructura y atribuciones de estos no eran precisamente los de un organismo de jurisdicción constitucional que ejerce su acción de forma plena. Así, en la Constitución de 1945 se crea el Tribunal de Garantías Constitucionales (TGC) como un órgano de control constitucional, dependiente de los demás poderes del Estado, con escasas competencias para realizar el control sobre la ley. En el presente artículo se realizará un breve análisis de la evolución de la jurisdicción constitucional en el Ecuador. A partir de la Constitución de 2008, la forma de concebir la organización del Estado en el Ecuador tiene un impacto directo sobre el control judicial de constitucionalidad, dado que todos los jueces ocupan un sitio estelar como custodios de los derechos de quienes acuden ante 
la administración judicial. Así sucede, al menos, en el plano formal, pues en la práctica jurisdiccional existe una brecha marcada entre el diseño formal y la materialización del estado de derechos. No obstante, la declaración de inconstitucionalidad de la ley es una competencia exclusiva de la Corte Constitucional. Los jueces de los distintos tribunales se limitan a realizar un trabajo colaborativo con el órgano encargado de la jurisdicción constitucional. Dicho esto, se ha proscrito de manera tajante la posibilidad de que los jueces ordinarios declaren la inconstitucionalidad de cualquier norma jurídica.

\section{Palabras Clave}

control constitucional - Estado - jueces - derechos - justicia.

\section{Abstract}

The approval of the Constitution of the Republic of Ecuador (CRE) in 2008 marked a major shift in the paradigm of Ecuadorian constitutional law. From that moment on, and in light of the new state of rights and social justice enshrined in the Constitution, the Constitutional Court (CC) was conceived for the first time as a specialized body independent from the other functions of the State. It should be noted that during the twentieth century Constitutional Courts were also instituted, but their structure and powers were not precisely those of a body with constitutional jurisdiction that fully exercises its action. Thus, the 1945 Constitution created the Court of Constitutional Guarantees (TGC) as a body of constitutional control, dependent on the other powers of the State, with little competence to carry out control over the law. In this article, a brief analysis will be made of the evolution of constitutional jurisdiction in Ecuador. Since the 2008 Constitution, the way in which the State is organized in Ecuador has a direct impact on judicial control of constitutionality, given that all judges occupy a stellar position as guardians of the rights of those who come before the judicial administration. This is the case, at least formally, since in jurisdictional practice there is a marked gap between the formal design and the materialization of the rule of law. Nevertheless, the declaration of unconstitutionality of the law is an exclusive competence of the Constitutional Court. The judges of the various courts limit themselves to collaborative work with the organ in charge of constitutional jurisdiction. That said, the possibility of ordinary judges declaring the unconstitutionality of any legal norm has been strictly outlawed.

\section{Keywords}

constitutional control - Status - Judges - rights - justice. 
SUMARIO: I. INTRODUCCIÓN. II. El ESTADO DE DEREChOS Y LA JUSTICIA CONSTITUCIONAL. III. ROL DE LOS JUECES EN EL DESARROLLO DEL CONTROL JUDICIAL DE CONSTITUCIONALIDAD. IV. LA TEXTURA ABIERTA EN EL LENGUAJE DEL DERECHO (HART). V. CONTROL JUDICIAL DE CONSTITUCIONALIDAD SOBRE LAS NORMAS JURÍDICAS. VI. EL CONTROL DiFuso DE CONSTITUCIONALIDAD. VII. CONCLUSIONES. BibliogRafía.

\section{INTRODUCCIÓN}

Sin duda alguna, la Constitución de la República del Ecuador (CRE), aprobada el 20 de octubre de 2008 en Montecristi -Ciudad Alfaro, marca un giro transcendental en el paradigma del derecho constitucional ecuatoriano. La organización estatal pasó de ser entendida como un estado de derecho a un estado de derechos y justicia, según lo describe el Art. 1 de la propia Constitución. Ello no solo conduce a una transformación en el campo de las libertades de las personas centrada en los derechos subjetivos y los fines del Estado, sino que además implica una nueva concepción respecto al control judicial de constitucionalidad aplicado en el Ecuador, en la medida en que se implanta, por primera vez en la historia republicana, un organismo especializado e independiente de las demás funciones del Estado para resolver los asuntos concernientes al ámbito constitucional, como es la Corte Constitucional (CC), máxima intérprete de la Constitución.

Es cierto que en varias de las anteriores cartas fundamentales del Ecuador se instituyeron Tribunales Constitucionales, sin embargo, la estructura y atribuciones de estos no eran precisamente las de un organismo que ejerce su acción de forma plena y exclusiva como jurisdicción constitucional. Así, en la Constitución de 1945 se introdujo, por vez primera, el Tribunal de Garantías Constitucionales (TGC) como órgano de control constitucional, en reemplazo del Consejo de Estado; no obstante, muchas de las atribuciones que le fueron conferidas no eran propias de la jurisdicción constitucional (Salgado: 2008 , 157). Con escasas competencias, las funciones del Tribunal se limitaban a la suspensión temporal de las leyes, ya que era el Congreso Nacional el que ostentaba de forma exclusiva la atribución de declarar su inconstitucionalidad.

El TGC será eliminado de las subsiguientes normas fundamentales. Reaparecerá, sin embargo, en la Constitución de 1967, si bien continúa sin estar facultado para pronunciarse sobre la inconstitucionalidad de la ley. En 1979, tras el fin de la dictadura militar, se aprueba una nueva Constitución, que prevé también la existencia de un Tribunal Constitucional (TC), aunque con atribuciones igualmente limitadas, dado que no logra consolidar su posición como principal órgano que ejerce el control de constitucionalidad de la ley. 
El poder Legislativo es el máximo intérprete de la Constitución, y solo a través de sus resoluciones es posible declarar la inconstitucionalidad de la ley con efectos generales. Además, las Salas de la Corte Suprema aplicaban el control abstracto sobre las leyes, decretos y reglamentos; y, por su parte, los tribunales de última instancia tenían entre sus atribuciones la potestad de inaplicar la ley para cada caso concreto (art. 138 Constitución de 1979).

Con las reformas constitucionales efectuadas en 1992 el TGC se convierte en el encargado de aplicar, en primera instancia, el control abstracto de constitucionalidad, mientras que la Sala de lo Constitucional de la Corte Suprema de Justicia ejecuta el control de la ley en última instancia, de forma que sus sentencias producen efectos generales (Salgado: 2008, 163). Lo cierto es que, durante este periodo, en el Ecuador se implementó una suerte de control dual de constitucionalidad, al haberse instaurado una jurisdicción constitucional de doble instancia, en manos de dos órganos con diferentes competencias.

Finalmente, en la reforma constitucional de 1996 el TC será designado como el encargado de aplicar el control de constitucionalidad sobre la ley, convirtiéndose así en la instancia definitiva para resolver los procesos judiciales en materia constitucional. Merece la pena destacar que esta reforma constitucional permitió la introducción de la acción de amparo y el habeas data como garantías jurisdiccionales. Más adelante, en la Constitución Política del Ecuador de 1998 se implementó el control difuso de constitucionalidad, de forma que todos los jueces se encontraban facultados para examinar la constitucionalidad de la ley, generando sus sentencias efectos inter partes. Con el fin de evitar que en casos análogos se produjeran distintas interpretaciones respecto a la constitucionalidad de una norma, el TGC realizaba el control posterior de las sentencias emitidas por los jueces de la justicia ordinaria.

A partir de la Constitución de 2008, la forma de concebir la organización del Estado en el Ecuador tiene un impacto directo sobre el control judicial de constitucionalidad, dado que todos los jueces ocupan un sitio estelar como custodios de los derechos de quienes acuden ante la administración judicial. Así sucede, al menos, en el plano formal, pues en la práctica jurisdiccional existe una brecha marcada entre el diseño formal y la materialización del estado de derechos. «El juez, en un estado constitucional, no puede ser solamente 'boca de la ley'. El juez tiene que aplicar principios que constan en la Constitución y convertirse en 'cerebro y boca de la Constitución'» (Ramiro Ávila Santamaría: 2011, 124). Es preciso, por tanto, prestar especial atención al rol de los jueces dentro del garantismo constitucional, tanto desde una perspectiva formal como en el ejercicio de la práctica judicial.

La configuración del ordenamiento jurídico ecuatoriano como Estado constitucional de derechos y justicia social no es una mera cuestión 
semántica, antes bien, conlleva un cambio radical en la comprensión del propio ordenamiento jurídico. En el campo normativo se pasó del imperio de la ley al estilo kelseniano, tal y como se había concebido en las Constituciones durante el siglo XX, a una «Constitución viva», en palabras de Peter Häberle (2013), a inicios del siglo XXI. En el «nuevo momento constitucional» ecuatoriano, la comprensión del ordenamiento jurídico se debe hacer a la luz de los derechos fundamentales que emanan de la Constitución y los instrumentos internacionales ratificados por el Estado. Se ha de garantizar su cumplimiento con la misma fuerza coercitiva que revisten las demás normas del ordenamiento jurídico. De este modo, los derechos, dentro del marco constitucional, dejaron de ser una mera declaración o aspiración social, que el Estado de forma aparente garantizaba por el solo hecho de no limitar su ejercicio, y pasaron a convertirse en un imperativo constitucional. Esto es, el Estado no solo debe no limitar el ejercicio de los derechos, sino que además tiene la obligación de crear las condiciones necesarias para que este sea posible por parte de todos los sujetos concernidos.

En el marco de este nuevo orden constitucional que impera en el Ecuador, se entiende que tanto las reglas como los principios son normas constitucionales de igual jerarquía que deben ser aplicadas de una forma rápida, sencilla y eficaz, conforme se establece en la Convención Americana sobre Derechos Humanos de $1969^{1}$. De esta forma, los principios y derechos constitucionales poseen por sí mismos fuerza de norma jurídica, de cara a su aplicación y cumplimiento, según lo que se puede deducir del principio de objetividad normativa que se recoge en el art. 11.3 $\mathrm{CRE}^{2}$. Por tanto, en un estado de derechos no deben existir limitaciones al ejercicio pleno de las libertades inherentes a todos los seres humanos, salvo cuando con ello se pongan en riesgo los derechos individuales o colectivos de los demás.

De este modo, la garantía de la aplicación inmediata y directa de los derechos de las partes procesales que se establecen en la Constitución y en los instrumentos internacionales demanda inexorablemente la asunción de este nuevo paradigma constitucional por parte de todos los integrantes de la función judicial y, especialmente, de la justicia constitucional. Su éxito depende,

${ }^{1}$ Artículo 25. Protección Judicial 1 CADH: «Toda persona tiene derecho a un recurso sencillo y rápido o a cualquier otro recurso efectivo ante los jueces o tribunales competentes, que la ampare contra actos que violen sus derechos fundamentales reconocidos por la Constitución, la ley o la presente Convención, aun cuando tal violación sea cometida por personas que actúen en ejercicio de sus funciones oficiales».

2 Art. 11 CRE: «El ejercicio de los derechos se regirá por los siguientes principios: (...) 3. Los derechos y garantías establecidos en la Constitución y en los instrumentos internacionales de derechos humanos serán de directa e inmediata aplicación por y ante cualquier servidora o servidor público, administrativo o judicial, de oficio o a petición de parte». 
en buena medida, de la estructuración de un sistema de justicia rápido, sencillo y eficaz, sin dilaciones o atascos innecesarios. De igual forma, la actuación de la justicia constitucional tampoco se podrá ver sometida a obstáculos que dificulten o hagan imposible una efectiva tutela judicial.

\section{EL ESTADO DE DERECHOS Y LA JUSTICIA CONSTITUCIONAL}

Desde la óptica constitucional ecuatoriana se concibe al Estado como una forma de organización de la sociedad en la que los derechos por sí solos generan obligaciones entre el propio Estado y los ciudadanos, sin que sea precisa una regla expresa para que aquellos se encuentren garantizados y sean eficaces. En este escenario jurídico, en el que rige el imperio de los derechos, con su efecto irradiación vinculante a todas las decisiones que se tomen dentro del Estado, los jueces, al administrar justicia, deben asumir un rol activo, a fin de tutelar de manera efectiva dichos derechos, conforme se deriva de los elementos constitutivos del Estado. En este sentido, según dispone el art. 1 CRE, «el Ecuador es un Estado constitucional de derechos y justicia, social, democrático, soberano, independiente, unitario, intercultural, plurinacional y laico. Se organiza en forma de república y se gobierna de manera descentralizada». Con claridad se puede vislumbrar que la redacción de este artículo no contiene un error semántico o es fruto de la mera casualidad al emplear el término «derechos» en lugar de «Derecho», sino que, por el contrario, a partir de esta fórmula surge la obligación de todos los miembros del Estado ecuatoriano de constitucionalizar sus acciones a través de la aplicación de los principios y derechos fundamentales, en todas las esferas de decisión, tanto públicas como privadas.

Desde que el garantismo constitucional se instaló en el ordenamiento jurídico ecuatoriano a partir del año 2008, resulta inevitable efectuar un análisis del contenido de la Constitución vigente para entender su fuerza vinculante y prevalencia sobre el resto del ordenamiento jurídico, así como lo que ello representa, particularmente en relación con el sistema de administración de justicia y el rol de los jueces, pues las garantías jurisdiccionales permiten corregir las alteraciones del orden constitucional, es decir, instrumentalizar el desarrollo del estado de derechos. A tal efecto, merece la pena que recordemos las palabras de Bidart Campos, recogidas por Ferreyra, respecto a la fuerza vinculante de la Constitución:

«El documento constitucional escrito de un Estado democrático es un sistema normativo que tiene fuerza obligatoria y vinculante, es decir, que reviste la naturaleza de norma jurídica, descartando absolutamente la posibilidad de que la constitución pueda ser considerada -parcial o totalmenteun texto donde se acumulen ruegos, simples declaraciones o parámetros 
orientativos. Su proposición es que la constitución de un Estado democrático tiene fuerza normativa en toda su integridad, en todas sus partes, en todos sus contenidos, también en sus implicitudes.» (Ferreyra: 2016, 144)

Entender, en palabras de Bidart Campos, la fuerza obligatoria y vinculante del estado de derechos que rige en el ordenamiento jurídico del Ecuador supone mirar de frente al rol que cumplen en la actualidad los jueces para el desarrollo de las garantías constitucionales. De ahí la afirmación de que la Constitución «vale lo que valen sus garantías» (Ferreyra: 2016, 161), ya que la justicia constitucional requiere tener como centro de su aplicación los principios y derechos reconocidos en la Ley Fundamental, así como aquellos otros que están implícitos en su esencia. No es una labor sencilla, pero sí imprescindible, contar con jueces plenamente comprometidos con el desarrollo de esta pionera forma de concebir el orden constitucional dentro del Estado ecuatoriano.

La justicia constitucional, concebida desde un Estado que funda su actuación en los derechos, necesita de los instrumentos necesarios para hacer viable su validez formal en la práctica. Si bien es cierto que en el Ecuador existe una Corte especializada en el ámbito constitucional, ello no significa que sea el único órgano que debe atender la prevalencia del orden constitucional, pues esta es una tarea de todos los órganos del Estado. De esta forma, el estado de derechos se presenta como un cambio radical en las relaciones jurídicas preexistentes, ya que obliga a resolver desde la Constitución problemas que anteriormente solo se podían solucionar a través del derecho positivo infraconstitucional.

Según señala Luigi Ferrajoli, «[e]l constitucionalismo, tal como resulta de la positivización de los derechos fundamentales, como límites y vínculos sustanciales a la legislación positiva, corresponde a una segunda revolución en la naturaleza del derecho que se traduce en una alteración interna del paradigma positivista clásico» (Ferrajoli: 2010, 66). Fácilmente se puede deducir que en este nuevo orden el positivismo sufre una gran transformación, en la medida en que los derechos de los ciudadanos se erigen sobre todo el conjunto de reglas jurídicas establecidas. Aunque las mismas se encuentren dentro de la Carta constitucional estarán sometidas al imperio de los principios y derechos.

\section{III.ROL DE LOS JUECES EN EL DESARROLLO DEL CONTROL JUDICIAL DE CONSTITUCIONALIDAD}

En el Ecuador los jueces son garantes del Estado constitucional de derechos y justicia, con la potestad de resolver las causas en función de la normatividad constitucional. Sin embargo, la tutela judicial efectiva y la objetividad normativa son presupuestos constitucionales que en la práctica no han logrado materializarse de forma eficaz. Los principios constitucionales sobre 
los que se desarrolla la tutela judicial efectiva se encuentran recogidos en el art. $75 \mathrm{CRE}$, a cuyo tenor «[t]oda persona tiene derecho al acceso gratuito a la justicia y a la tutela efectiva, imparcial y expedita de sus derechos e intereses, con sujeción a los principios de inmediación y celeridad; en ningún caso quedará en indefensión. El incumplimiento de las resoluciones judiciales será sancionado por la ley».

La CC es el máximo organismo de interpretación y control constitucional, su función es garantizar que las normas jurídicas sean aplicadas por los jueces con estricta observancia de la Constitución. Es un órgano independiente, cuenta con autonomía administrativa y financiera, integrado por nueve jueces, designados por un periodo de nueve años. Los miembros de la $\mathrm{CC}$ son designados por el Consejo de Participación Ciudadana y Control Social y no pueden ser removidos por este organismo, además, tampoco pueden ser reelegidos de manera inmediata (arts. 429 ss. CRE).

Tanto los jueces de la CC como los jueces de la justicia ordinaria se encuentran llamados a hacer efectivas las garantías constitucionales. La jurisdicción ordinaria no puede quedar restringida a la mera aplicación de las reglas jurídicas, debiendo guiar sus pronunciamientos por las normas y principios constitucionales. Materializar el estado de derechos conforme a la Constitución es una tarea predicable de todos los jueces, con independencia de cuál sea su categoría, no solo de los que integran la CC. Así lo dispone el art. 426 CRE, al afirmar que «[1]as juezas y jueces, autoridades administrativas y servidoras y servidores públicos, aplicarán directamente las normas constitucionales y las previstas en los instrumentos internacionales de derechos humanos siempre que sean más favorables a las establecidas en la Constitución, aunque las partes no las invoquen expresamente».

De acuerdo con la Constitución vigente, por tanto, todos los jueces son parte de la jurisdicción constitucional, ya que tienen el deber de garantizar la supremacía de la Constitución sobre las demás normas del ordenamiento jurídico. No obstante, se ha proscrito de manera tajante la posibilidad de que los jueces ordinarios declaren la inconstitucionalidad de cualquier norma jurídica. Corresponde de forma exclusiva a los jueces que integran la CC resolver las posibles contradicciones que surjan entre la ley y la Constitución. Una garantía jurisdiccional que permite alertar de posibles inconstitucionalidades al aplicar la ley en casos concretos es la consulta de constitucionalidad de la norma. Esta acción es presentada por el juez ante la CC, a petición de alguna de las partes o de oficio, siempre y cuando, a criterio del juez, existan motivaciones suficientes. De esta manera, se evita que cada juez, en casos análogos, redacte sentencias distintas en función de la interpretación discrecional que pudieran realizar de la norma fundamental

Dicho de otro modo, mientras que los jueces pertenecientes al sistema de justicia ordinario ejercen un control constitucional positivo al considerar que 
la ley es sustancialmente valida, la CC, por su parte, ejecuta un control de carácter negativo cuando declara inconstitucional la ley que ha sido sometida a consulta. Tal como se encuentra diseñado, el sistema de justicia constitucional en el Ecuador garantiza a las personas cierto grado de certeza respecto a la interpretación de la ley realizada por los jueces, ya que se encuentran sujetos a los dictámenes de la CC. Desde otra perspectiva, se puede entender que esta solución puede llegar a suponer el menoscabo de la facultad de los jueces de aplicar los principios constitucionales de forma inmediata y directa, como es lo propio en un estado de derechos. No obstante, la labor cognitiva de interpretación constitucional de los jueces de instancia debe ser comprendida dentro del marco del activismo judicial y del principio de objetividad normativa, que se encuentra recogido en el art. 11.6 CRE, de acuerdo con el cual « $[\mathrm{t}]$ odos los principios y los derechos son inalienables, irrenunciables, indivisibles, interdependientes y de igual jerarquía».

Por su parte, la CC, a raíz de la sentencia No 001-13-SCN-CC (2013), ha establecido expresamente que en Ecuador existe el control concentrado de constitucionalidad:

«En el Ecuador existe únicamente el control concentrado de constitucionalidad, por lo que le corresponde solo a la Corte Constitucional la declaratoria de inconstitucionalidad de una norma y su consecuente invalidez. De este modo, si bien las juezas y jueces tienen la obligación de advertir la existencia de disposiciones normativas contrarias a la Constitución, siempre deben consultar a la Corte Constitucional para que sea esta la que se pronuncie respecto a su constitucionalidad»

De conformidad con esta sentencia, por consiguiente, en el Ecuador los jueces de instancia tienen fijado un límite inflexible que prohíbe la declaración de inconstitucionalidad de normas al conocer de un caso concreto, lo que, a su vez, resulta incongruente en un Estado en el que priman los derechos. Si bien es cierto que el control concentrado de constitucionalidad permite garantizar la uniformidad de los fallos en materia constitucional, siendo su principal característica su carácter vinculante y erga omnes, la forma tan rígida en que ha sido concebido por parte de la CC limita, sin embargo, la aplicación rápida, sencilla y eficaz de la tutela judicial efectiva, sin mencionar la excesiva carga procesal a la que esta queda sometida.

Además, se debe tener en cuenta la textura abierta del Derecho, entendiendo que los términos jurídicos usados surgen a partir del mismo lenguaje empleado en la vida cotidiana, lo que supone que, en numerosas ocasiones, en el campo del Derecho, así como en la vida cotidiana, las palabras tengan un contenido indeterminado, lo que dificulta su comprensión en situaciones complejas si no se conoce el contexto que rodea a la realidad. A tal efecto, debe ser una labor de todos los jueces, como última alternativa, crear 
derechos cuando, en un caso concreto que esté bajo su conocimiento, se transite bajo esta «zona de penumbra» (Pannam: 2008, 77).

Como resulta evidente, las complejidades fácticas habituales que se presentan dentro de los casos concretos en los que el juez debe administrar justicia, dificultan la aplicación del ordenamiento jurídico haciendo uso exclusivo de la lógica por medio de la subsunción de las normas positivizadas. Tal y como señala Ferreyra (2016: 67), «[e]l juez no es un autómata, ni la actividad jurisdiccional una maquinaria. Y es por tal razón que vale la afirmación de que los jueces crean Derecho. El derecho no está acabado ni en los supuestos en los cuales los jueces analizan el discurso (...); ni en los supuestos en los cuales los jueces adjudican o asocian, bajo su única y exclusiva responsabilidad, un significado jurídico a las expresiones lingüísticas (...)».

Como se ha indicado, el estado de derechos se fundamenta en la inmediata y directa aplicación de las libertades ciudadanas. Sin embargo, la Constitución señala en su art. 428 que, en casos de consulta de constitucionalidad de la norma por parte de un juez de instancia, la CC deberá resolver la acción en un plazo no superior a 45 días, y en caso de no ser resuelta el perjudicado podrá interponer la acción correspondiente ${ }^{3}$. En parte, esta disposición constitucional entra en colisión con el principio, igualmente constitucional, de objetividad normativa, al limitar las competencias del juez de instancia en un caso en el que se ha planteado una consulta y la $\mathrm{CC}$ no ha emitido pronunciamiento alguno al respecto. En situaciones como estas, ante la aparente colisión de dos normas constitucionales, la $\mathrm{CC}$ debe interpretar la Constitución de modo tal que se garantice la validez de ambas disposiciones, así como su aplicación en el sentido que más se ajuste a su contenido integral.

Estas situaciones excepcionales implican una grave vulneración de los derechos de una de las partes procesales; vulneración que podría ser evitada mediante la acción eficaz del juez de instancia, a fin de hacer prevalecer el estado de derechos. Resulta, por consiguiente, imprescindible incorporar un nuevo mecanismo constitucional eficaz para que el juez pueda actuar en estas circunstancias.

A este respecto, de una lectura integral de la Constitución ecuatoriana, a partir de la lógica del garantismo constitucional, cabría entender que los

${ }^{3}$ Art. 428 CRE: «Cuando una jueza o juez, de oficio o a petición de parte, considere que una norma jurídica es contraria a la Constitución o a los instrumentos internacionales de derechos humanos que establezcan derechos más favorables que los reconocidos en la Constitución, suspenderá la tramitación de la causa y remitirá en consulta el expediente a la Corte Constitucional, que, en un plazo no mayor a cuarenta y cinco días, resolverá sobre la constitucionalidad de la norma.

Si transcurrido el plazo previsto la Corte no se pronuncia, el perjudicado podrá interponer la acción correspondiente». 
jueces, bajo determinadas circunstancias especificadas en la propia Constitución o en la ley correspondiente, deberían tener la facultad de administrar justicia en los casos que consideren que una norma jurídica supone un grave riesgo para el estado de derechos.

Pero lo cierto es que la $\mathrm{CC}$ ha cerrado las puertas a la posibilidad de aplicar una especie de control difuso excepcional por parte de los jueces de instancia, atribución que en la actualidad no se encuentra establecida dentro del ordenamiento jurídico del Ecuador, si bien sí permitiría, en función del grado de vulneración de los principios o derechos constitucionales, que el juez a cargo de sustanciar el proceso se pueda excepcionar de seguir el procedimiento previsto por la Ley orgánica de garantías jurisdiccionales y control constitucional, específicamente en los casos en que, planteada la acción de consulta de constitucionalidad, la CC no resuelva la consulta del juez dentro de los plazos que establece la Constitución y la ley. En estas circunstancias, el juez podría declarar inconstitucional una norma con efecto inter partes, sin perjuicio de que esa decisión estuviera después sujeta a un rígido control posterior por parte de la CC. Inevitablemente, surgiría aquí una fricción intraorgánica, en la medida en que la acción de un órgano jurisdiccional afectaría a las competencias originarias del legislador, fricción que, pese a no ser deseable, podría ser excepcionalmente necesaria. Como ha señalado Ramiro Ávila, «[e]l poder para resolver conflictos entre órganos o por exceso en sus atribuciones, se transfiere del parlamento a los jueces que tienen competencia constitucional» (Ávila: 2011, 112). Instaurar este procedimiento implicará llevar a cabo una reforma urgente del art. 428 CRE y, de manera concomitante, de las normas infraconstitucionales relacionadas con el mismo.

Lo anotado en líneas anteriores no implica desconocer que los jueces, con carácter general, tienen un límite para ejercer el control judicial de la Constitución frente a las competencias conferidas al legislador y a la CC. Sin embargo, resulta necesario que en el ordenamiento jurídico ecuatoriano se establezcan procedimientos, ante situaciones excepcionales y específicas, capaces de generar la suficiente confianza en la administración de justicia. Este procedimiento puede generar dos efectos positivos en la jurisdicción constitucional: Conminar a la $\mathrm{CC}$ a cumplir con sus atribuciones de una forma rápida y eficaz; y garantizar el acceso a la tutela judicial efectiva a todos los ciudadanos, bajo cualquier circunstancia, más allá de los hechos fácticos.

Para finalizar este apartado es pertinente mencionar el fallo de la $\mathrm{CC}$ del Ecuador $\mathrm{N}^{\circ}$ 020-10-SEP-CC, en el que se refiere al importante rol de los jueces dentro del sistema constitucional de derechos y justicia implantado:

«La nueva corriente del constitucionalismo cuestiona la posición del juez como un simple 'director del proceso' o espectador; mira al juez imbuido en el activismo judicial, que hace suya la garantía constitucional de 
la tutela judicial efectiva; cumple un papel mucho más proactivo e investigativo, más comprometido en lograr la verdad procesal, tomando como puntos referenciales y obligados el ordenamiento jurídico y la realidad social; es decir, siendo 'el custodio responsable del derecho sustancial disputado por las partes, y perceptivo de las condiciones materiales o sociales que rodean al hecho; dando énfasis a la necesidad de la defensa en juicio o comparecencia de las partes en equidad, con poder suficiente para disponer medidas de tutela urgente, o preventivas, también llamadas medidas de satisfacción inmediata o precautorias, y reafirmando su voluntad de dar a cada uno su derecho en el momento oportuno» (Acción Extraordinaria de Protección, 2010).

\section{IV.LA TEXTURA ABIERTA EN EL LENGUAJE DEL DERECHO (HART)}

En el presente apartado se abordará la concepción del constitucionalismo ecuatoriano a la luz de la teoría de Hart sobre el uso del lenguaje y su valor indeterminado en el desarrollo de las normas jurídicas, lo que nos permitirá reconocer que existen casos en los cuales los hechos no se logran adecuar a la generalidad de la norma para poder ser resueltos de forma simple a través de la interpretación analítica, siendo preciso guiarse por los principios constitucionalmente reconocidos para dar una solución atípica a lo prescrito por el ordenamiento jurídico. Aun cuando suponga adelantar conclusiones, la idea final pasa por defender la necesidad de reformar la Constitución de la República del Ecuador en el sentido de garantizar que los jueces de instancia puedan, de forma especialísima, inaplicar normas jurídicas en un caso concreto al ser consideradas opuestas a los principios y derechos que se establecen en la Constitución.

Interesa, en este punto, traer a colación las siguientes palabras de Ferreyra: «[e]1 reconocimiento de la Constitución como norma jurídica supone la configuración de una herramienta para el control y, por ende, la limitación del poder. El carácter normativo de la Constitución quiere significar que no estamos en presencia de un mero catálogo de principios, sino de una norma cuyo contenido vincula de modo inmediato a todos los ciudadanos y poderes públicos. Por lo demás, sus preceptos, como regla general, son alegables ante los tribunales y su infracción debe considerarse antijurídica» (Ferreyra: 2015, 141).

$\mathrm{Si}$-como afirma Ferreyra- infringir los preceptos constitucionales es una conducta antijurídica, entonces todos los jueces deben ser entendidos como operadores de justicia especializados que optimizan el desarrollo de la jurisdicción constitucional, $\mathrm{y}$, como tales, son responsables de la obra del deber ser del derecho. En consecuencia, no pueden estar proscritas sus competencias para resolver inconstitucionalidades en los casos de que tuvieren conocimiento, pues de conformidad con las consideraciones realizadas en párrafos anteriores, 
cabe entender que el lenguaje del Derecho es indeterminado, con cierta vaguedad para poder ser aplicado en función de la casuística general.

La corriente neo constitucionalista obliga a los jueces de todos los niveles a buscar la vía más idónea para garantizar la aplicación más favorable al contenido formal y sustancial de la Constitución, protegiendo los derechos consagrados en el marco jurídico. En palabras de Hart: «Los casos claros, en que los términos generales parecen no necesitar interpretación y el reconocimiento de los ejemplos parece ser «automático», son únicamente los casos familiares que se repiten en forma constante en contextos semejantes» (Hart: 1961, 162). De aquí se deduce que no todos los casos se ajustan con claridad al precepto jurídico que se determina en la norma jurídica, pues hay casos que se encuentran en la «zona de penumbra» y que deben ser tratados por el derecho de una forma particular, instrumentando procedimientos especiales que permitan a los jueces expulsar del orden jurídico normas que vulneran, en el caso específico, derechos. Este camino en la actualidad se encuentra cerrado por la CC.

Y es que, según destaca Hart, «[1]a textura abierta del derecho significa que hay, por cierto, áreas de conducta donde mucho debe dejarse para que sea desarrollado por los tribunales o por los funcionarios que procuran hallar un compromiso, a la luz de las circunstancias, entre los intereses en conflicto, cuyo peso varía de caso a caso. (...) Aquí en la zona marginal de las reglas y en los campos que la teoría de los precedentes deja abiertos, los tribunales desempeñan una función productora de reglas, que los cuerpos administrativos desempeñan centralmente en la elaboración de standards variables» (Hart: 1961, 168-169).

La justicia constitucional, dentro de un Estado donde imperan los derechos por encima de los actos normativos, como es el caso de Ecuador, debe garantizar que todo problema jurídico pueda ser resuelto por los órganos judiciales, desde un caso tan trivial que solo requiere de una simple acción repetitiva aplicando la lógica del derecho, hasta aquellos otros casos que se encuentran en zonas de penumbra, difíciles de resolver por su complejidad factual. En consecuencia, resulta necesario facultar a los jueces de cualquier instancia, bajo estrictos criterios emanados de una reforma constitucional, o de los fallos de la CC, para resolver procesos judiciales que requieran inaplicar normas jurídicas para un caso en concreto, lo que forma parte de las fronteras aún inexploradas del nuevo orden constitucional del Ecuador, orientado hacia la materialización de los derechos.

\section{CONTROL JUDICIAL DE CONSTITUCIONALIDAD SOBRE LAS NORMAS JURÍDICAS}

Como es bien conocido, existen dos sistemas clásicos de jurisdicción constitucional: el modelo de control difuso o americano y el modelo de 
control concentrado o europeo, ideado por Kelsen e implementado por primera vez en la Constitución austriaca de 1920. Al analizar, desde una perspectiva diacrónica, las formas de control adoptadas, tanto en los países europeos como americanos, se puede observar que, con posterioridad a la Segunda Guerra Mundial, se produjo una cierta hibridación de ambos modelos, dando origen a la conformación de sistemas mixtos o duales. De este modo, podemos observar que en la actualidad hay Estados que han implementado sistemas de control constitucional en los que en su configuración inicial predominan características del control difuso o del concentrado, si bien hay otros en los que coexisten ambas formas de control de manera pareja. Fix-Zamudio lo señala con claridad:

«En la práctica estos elementos aparecen matizados, y si bien el predominio de varios de ellos nos permite calificar a un sistema de americano o de austríaco, no podemos considerarlos en forma pura, en virtud de que existe la tendencia hacia su combinación por medio de sistemas que utilizan las ventajas de ambos y eluden los inconvenientes de una estructura rígida, por lo que se han creado los llamados «sistemas mixtos»...» (FixZamudio: 1999, 97).

Podemos concluir que, en realidad, los sistemas de control constitucional responden a las configuraciones jurídicas y sociales propias de cada país. Dado que el presente trabajo tiene como finalidad analizar las implicaciones del cambio del paradigma constitucional en el Ecuador y sus efectos en la jurisdicción constitucional, no podemos detenernos en el estudio extenso de las características de los modelos clásicos del control constitucional, así como los distintos sistemas que se pueden forman a partir de su hibridación. Basta, pues, con dejarlos apuntados.

Las observaciones realizadas al control judicial de constitucionalidad ecuatoriano surgen a partir de la atribución a la CC de la competencia exclusiva para declarar la inconstitucionalidad de normas, lo que conlleva una restricción tajante del activismo judicial en manos de los demás jueces, lo que contrasta con el nuevo orden constitucional implantado en el Ecuador desde 2008, pues ante una consulta de inconstitucionalidad planteada por un juez en virtud del art. $428 \mathrm{CRE}$, y pese a no existir el pronunciamiento de la CC dentro del plazo establecido por la norma fundamental, el juez deberá continuar con la sustanciación de la causa, aun cuando considere que desde la concepción misma del nuevo estado de derechos la norma que ha de ser aplicada en el caso concreto es, total o parcialmente, inconstitucional. Este acto de omisión en el que puede incurrir la CC, pese a encontrarse amparado por el art. $428 \mathrm{CRE}$, en concordancia con el art. 142 de la Ley orgánica de garantías jurisdiccionales y control constitucional (LOGJCC), resulta, sin embargo, contradictorio con el principio de objetividad normativa. 
Estas contradicciones contrastan con el activismo judicial que impera en la Constitución y el principio de la tutela judicial efectiva establecido en los arts. $75 \mathrm{CRE}$ y $25 \mathrm{CADH}$, así como con la finalidad del control concreto de constitucionalidad establecida en el art. 141 LOGJCC, a cuyo tenor:

«El control concreto tiene como finalidad garantizar la constitucionalidad de la aplicación de las disposiciones jurídicas dentro de los procesos judiciales. Los jueces aplicarán las disposiciones constitucionales, sin necesidad que se encuentren desarrolladas en otras normas de menor jerarquía. En las decisiones no se podrá restringir, menoscabar o inobservar su contenido».

Resulta, además, inadmisible que por medio de una ley se distorsione el contenido de la Constitución en lo relativo al procedimiento para la sustanciación de consultas de constitucionalidad realizadas por los jueces de instancia. Lo que resulta aún más preocupante cuando la norma afecta al principio de objetividad normativa y al derecho a la tutela judicial efectiva, que, como ya se ha mencionado, son principios que en el sistema vigente se hallan revestidos de fuerza vinculante.

Ocurre, sin embargo, que en la LOGJCC se establece algo que no está contemplado en la Constitución respecto a la obligatoriedad de continuar sustanciando el trámite a pesar de no existir un pronunciamiento de la CC. Así, de acuerdo con el art. 142 LOGJCC, «(...) cualquier jueza o juez, de oficio o a petición de parte, sólo si tiene duda razonable y motivada de que una norma jurídica es contraria a la Constitución o a los instrumentos internacionales de derechos humanos que establezcan derechos más favorables que los reconocidos en la Constitución, suspenderá la tramitación de la causa y remitirá en consulta el expediente a la Corte Constitucional, la que en un plazo no mayor a cuarenta y cinco días resolverá sobre la constitucionalidad de la norma. Si transcurrido el plazo previsto la Corte Constitucional no se pronuncia, el proceso seguirá sustanciándose $(\ldots) »$.

Llegados a este punto, es posible afirmar que existe una cierta contradicción entre las normas recogidas en los arts. 11. 3 y 428 CRE, debido al estricto límite fijado a la acción de los jueces de instancia en aquellos casos en los que se presenta una acción de consulta de constitucionalidad de norma, y específicamente en los que la CC no ha emitido pronunciamiento alguno, lo que puede generar una afectación a los derechos de las partes procesales. Esta situación conduce inevitablemente a un conflicto jurídico interno del juez encargado de administrar justicia, que tiene lugar en aquellos casos en los que la CC, por su exceso de carga procesal, no resuelve la acción de consulta de constitucionalidad realizada, debiendo así el juez continuar con la sustanciación del proceso, pese a considerar que, a la luz del estado de derechos, la aplicación de una norma para el caso concreto es inconstitucional. 
Esta casuística pone de relieve, por tanto, una cierta contradicción entre los preceptos constitucionales referidos, pues al no ser resuelta la acción de consulta se presume la constitucionalidad de la norma vigente, sin que exista un análisis jurídico de los hechos facticos del proceso en concreto.

\section{VI.EL CONTROL DIFUSO DE CONSTITUCIONALIDAD}

Como es bien conocido, el control de constitucionalidad difuso, conocido como sistema americano, consiste en que los jueces de instancia durante la sustanciación de un proceso en concreto, al encontrarse frente a una inconstitucionalidad debidamente razonada y motivada, tienen la facultad de realizar el control constitucional e inaplicar la norma en cuestión. Si bien es cierto que el efecto de los fallos judiciales en este tipo de control es inter partes, se ha de evitar caer en ambigüedades o tener múltiples fallos para casos de similares características, pues algo así podría vulnerar la seguridad jurídica.

Es preciso, a tal efecto, recordar lo que establecía la anterior Constitución Política del Ecuador de 1998, en su art. 274: «Cualquier juez o tribunal, en las causas que conozca, podrá declarar inaplicable, de oficio o a petición de parte, un precepto jurídico contrario a las normas de la Constitución o de los tratados y convenios internacionales, sin perjuicio de fallas sobre el asunto controvertido».

No se trata ahora de reimplantar el control judicial de constitucionalidad previsto en la Constitución de 1998, pero sí de recoger ciertos elementos que permitan perfeccionar el actual control de constitucionalidad aplicado en el Ecuador por parte de la CC, que si bien es cierto que favorece la uniformidad de criterios en la administración de justicia, no deja de ser, sin embargo, excesivamente rígido frente a la proscripción de resolver inconstitucionalidades de las normas jurídicas en un caso concreto por parte de los jueces de instancia, quienes, como sabemos ya, también tienen el deber de garantizar la administración de justicia en el marco de los derechos constitucionales.

\section{CONCLUSIONES}

Se debe promover un proceso de reforma del art. 428 CRE y del art. 142 LOGJCC ante la Asamblea Nacional, por encontrarse limitados los principios de objetividad normativa y de tutela judicial efectiva fijados en los arts. 11.3 y 75 CRE, ya que establecen que, una vez culminado el plazo de cuarenta y cinco días para sustanciar la consulta de constitucionalidad, en caso de no pronunciarse la $\mathrm{CC}$, el juez de instancia deberá continuar con la sustanciación de la causa, reservándose el perjudicado el derecho de interponer la acción correspondiente. En casos excepcionales, el juez de instancia debería tener la potestad de resolver de forma motivada la inconstitucionalidad que 
subyace en el caso concreto, bajo un rígido control de estas acciones, sin necesidad de aplicar el procedimiento establecido en el art. $428 \mathrm{CRE}$.

La CC del Ecuador, en el marco de sus competencias, teniendo en consideración el rol activo que cumplen los jueces, el principio de objetividad normativa y la tutela judicial efectiva, ante la falta de acción del legislador y la apremiante necesidad de tutelar los derechos de los ciudadanos ecuatorianos, y a partir de la constatación de que, al igual que sucede en otros países latinoamericanos, en Ecuador existe también una marcada laxitud para tutelar los derechos por parte de los organismos estatales correspondientes, debería emitir una sentencia interpretativa a través de la cual establezca un procedimiento extraordinario de control difuso de constitucionalidad, exclusivo para los casos en los que existe un riesgo de grave vulneración de derechos.

Resulta evidente que la reforma del art. $428 \mathrm{CRE}$, tal y como se ha planteado en líneas anteriores, pone en cuestión el principio de separación de poderes y de legitimidad democrática, principios sobre los cuales se ha construido la organización del Estado moderno. Sin embargo, esta vía puede ser considerada, y solo ser utilizada, como un mecanismo excepcional que genere efectos de forma exclusiva para las partes procesales, como ultima ratio frente a las omisiones normativas en las que puede llegar a incurrir el legislador, o a fin de aliviar la prolijidad en el ejercicio de las competencias del más alto tribunal del Estado en materia constitucional. Si bien es cierto que los jueces constitucionales no se encuentran investidos de legitimidad popular en vía directa, y mucho menos ostentan competencias legislativas originarias, al ser órganos jurisdiccionales, no es menos verdad que sus atribuciones emanan de la Constitución y, por ende, se legitiman de forma indirecta, tanto por el proceso al cual son sometidos para su designación, como por su eficacia en el ejercicio de sus funciones. En todo caso, la legitimidad democrática siempre es deseable, pero no es un factor restrictivo frente a las demás fuentes de legitimidad.

Sería inadmisible pues, que, dentro del moderno paradigma constitucional, el juez de instancia se viera obligado, por imperativo constitucional, a continuar sustanciando una causa contra su propio criterio. Esto podría deslegitimar la eficacia normativa de la Constitución y el rol que los jueces deben asumir en un modelo garantista de la misma como pretende serlo el ecuatoriano.

\section{BIBLIOGRAFIA}

Ávila Santamaría, R. (2011). El neoconstitucionalismo transformador: el Estado y el derecho en la Constitución de 2008. Quito- Abya Yala, Universidad Politécnica Salesiana. Universidad Andina Simón Bolívar, Sede Ecuador. Fundación Rosa Lusemburg 
Ferrajoli, L. (2010). Derechos y garantías. La ley del más débil. Madrid: Trotta, S.A.

Ferreyra, R. G. (2015). Fundamentos Constitucionales. Buenos Aires, Argentina: Ediar.

— (2016). Notas sobre Derecho Constitucional y Garantías (Segunda ed.). Buenos Aires, Argentina: Ediar.

Fix-Zamudio, H. (1999). Aproximación al Derecho procesal constitucional. Anuario iberoamericano de justicia constitucional, (3), 89-120.

HÄBERLE, P. (2013). La sociedad abierta de los interpretes constitucioanles. Contextos, $163-168$.

Hart, H. (1961). El Concepto de Derecho. Buenos Aires: Abeledo- Perrot S.A.

Pannam, C. (2008). El profesor Hart y la Filosofía analítica del Derecho. Academia. Revista sobre enseñanza del Derecho, 77.

SAlgado, H. (2008). La justicia constitucional en el Ecuador. Quito, Ecuador: Jahreszeiten Verl. 


\title{
APUNTES CRÍTICOS SOBRE EL CONTROL JUDICIAL DE CONSTITUCIONALIDAD EN EL ECUADOR
}

\author{
Critical notes on judicial control of constitutionality in \\ Ecuador
}

\author{
Gonzalo M. Gaibor Gallardo \\ Doctorando en Derecho Constitucional \\ Universidad Autónoma de Madrid \\ gonzalo.gaibor@estudiante.uam.es
}

http://dx.doi.org/10.18543/ed-68(2)-2020pp97-114

\section{Copyright}

Estudios de Deusto es una revista de acceso abierto, lo que significa que es de libre acceso en su integridad. Se permite su lectura, la búsqueda, descarga, distribución y reutilización legal en cualquier tipo de soporte sólo para fines no comerciales, sin la previa autorización del editor o el autor, siempre que la obra original sea debidamente citada y cualquier cambio en el original esté claramente indicado

Estudios de Deusto is an Open Access journal which means that it is free for full access, reading, search, download, distribution, and lawful reuse in any medium only for non-commercial purposes, without prior permission from the Publisher or the author; provided the original work is properly cited and any changes to the original are clearly indicated. 